\title{
Isometric exercise training for blood pressure management: a systematic review and meta-analysis to optimize benefit
}

\author{
Jodie D Inder, Deborah J Carlson, Gudrun Dieberg, James R McFarlane, Nicole CL Hess and Neil A Smart
}

The objective of our study was to examine the effects of isometric resistance training (IRT) on resting blood pressure in adults. We conducted a systematic review and meta-analysis of randomized-controlled trials lasting $\geqslant 2$ weeks, investigating the effects of isometric exercise on blood pressure in healthy adults (aged $\geqslant 18$ years), published in a peer-reviewed journal between 1 January 1966 to 31 January 2015. We included 11 randomized trials, totaling 302 participants. The following reductions were observed after isometric exercise training; systolic blood pressure (SBP) mean difference (MD) $-5.20 \mathrm{~mm} \mathrm{Hg}(95 \%$ confidence interval (Cl) -6.08 to $-4.33, P<0.00001)$; diastolic blood pressure (DBP) $\mathrm{MD}-3.91 \mathrm{~mm} \mathrm{Hg}(95 \% \mathrm{Cl}-5.68$ to -2.14 , $P<0.0001)$; and mean arterial blood pressure (MAP) MD $-3.33 \mathrm{~mm} \mathrm{Hg}(95 \% \mathrm{Cl}-4.01$ to $-2.66, P<0.00001)$. Sub-analyses showed males tended to reduce MAP MD $-4.13 \mathrm{~mm} \mathrm{Hg}(95 \% \mathrm{Cl}-5.08$ to -3.18$)$ more than females. Subjects aged $\geqslant 45$ years demonstrated larger reductions in MAP MD $-5.51 \mathrm{~mm} \mathrm{Hg}(95 \% \mathrm{Cl}-6.95$ to -4.06$)$ than those $<45$ years. Subjects undertaking $\geqslant 8$ weeks of IRT demonstrated a larger reduction in SBP MD $-7.26 \mathrm{~mm} \mathrm{Hg}(95 \% \mathrm{Cl}-8.47$ to -6.04$)$ and MAP MD $-4.22 \mathrm{~mm} \mathrm{Hg}(95 \% \mathrm{Cl}-5.08$ to -3.37$)$ than those undertaking $<8$ weeks. Hypertensive participants in IRT demonstrated a larger reduction in MAP MD $-5.91 \mathrm{~mm} \mathrm{Hg}(95 \% \mathrm{Cl}-7.94$ to -3.87$)$ than normotensive participants $\mathrm{MD}-3.01 \mathrm{~mm} \mathrm{Hg}(95 \%$ $\mathrm{Cl}-3.73$ to -2.29 ). Our study indicated that IRT lowers SBP, DBP and MAP. The magnitude of effect may be larger in hypertensive males aged $\geqslant 45$ years, using unilateral arm IRT for $>8$ weeks.

Hypertension Research (2016) 39, 88-94; doi:10.1038/hr.2015.111; published online 15 October 2015

Keywords: blood pressure; isometric exercise training; meta-analysis

\section{INTRODUCTION}

In light of the prevalence of hypertension ${ }^{1}$ the associated economic health-care costs are significant. In addition, although antihypertensive medications generally have minimal side-effect, they are perhaps efficacious in $50 \%$ of those prescribed treatment. ${ }^{2}$ Both European and North American treatment guidelines for primary and secondary prevention of hypertension recommend nonpharmacological lifestyle modifications as the first line of therapy, including increasing levels of physical activity. ${ }^{3,4}$ There is Class I, Level B evidence that $150 \mathrm{~min}$ weekly physical activity offers an alternative that may be used to complement anti-hypertensive medication, ${ }^{5}$ although optimal exercise training prescription remains unclear.

One important factor that may impact the effectiveness to lower blood pressure (BP) is the type of exercise performed. Recent analyses suggest isometric exercise may elicit $\mathrm{BP}$ reductions greater than those seen with dynamic aerobic and resistance exercise. ${ }^{6-8}$ Currently, dynamic aerobic endurance activity is the preferred exercise modality for BP management. However, adherence to aerobic exercise is often sub-optimal. ${ }^{9}$ Isometric exercise involves sustained contraction against an immovable load or resistance with no or minimal change in length of the involved muscle group. Aerobic exercise performance has been shown to be inversely related to hemodynamic measurements, ${ }^{10}$ similarly isometric activity has previously been associated with exaggerated hypertensive responses. Recent work has, however, suggested isometric handgrip activity may become a new tool in the non-pharmacological treatment of high BP. ${ }^{11,12}$ Previous metaanalyses have examined effects of endurance training, ${ }^{13}$ dynamic resistance training ${ }^{14,15}$ and isometric resistance training (IRT) on $\mathrm{BP}^{12}$ The findings showed that isometric resistance exercise does lower BP; however, the sample sizes of the trials to date are generally small. Recently, several isometric exercise training trials have been published that necessitate an updated search and for the first time subanalyses of patient and exercise program characteristics that optimize anti-hypertensive effects. Our meta-analysis is the first to examine which patient or exercise program characteristics are most likely to produce anti-hypertensive effects.

The aims of this work were: (i) to conduct a systematic review and meta-analysis quantifying the effects of IRT on the change in systolic BP (SBP), diastolic BP (DBP) and mean arterial pressure (MAP) in adults and (ii) to conduct sub-analyses to examine which patient

School of Science and Technology, University of New England, Armidale, New South Wales, Australia

Correspondence: Associate Professor NA Smart, School of Science and Technology, University of New England, Armidale, New South Wales 2351, Australia.

E-mail: nsmart2@une.edu.au

Received 2 July 2015; revised 3 August 2015; accepted 13 August 2015; published online 15 October 2015 
demographics and exercise program characteristics exhibited the largest BP changes.

\section{METHODS}

\section{Search strategy}

Potential studies were identified by conducting a systematic search using Pub Med, www.ncbi.nlm.nih.gov/pubmed (1 January 1966 to 31 January 2015), the Pub Med search strategy can be seen in the Supplementary Files (Supplementary Figure S1). CINAHL and the Cochrane controlled trials registry were also searched (1966-31 January 2015). The search strategy included the key concepts of hypertension, BP, isometric exercise, IRT, physical training and exercise training. These were combined with a sensitive search strategy to identify randomized-controlled and crossover trials. Reference lists of papers found were scrutinized for new references. All identified papers were assessed independently by two reviewers (JDI and GD), a third reviewer (NAS) was consulted to resolve disputes. Searches of published papers were also conducted up until 31 January 2015.

\section{Inclusions}

Randomized, controlled trials and cross-over studies of isometric exercise training in adults were included. There were no language restrictions.

\section{Exclusions}

Animal studies, review papers, acute exercise studies and non-randomized controlled trials were excluded. Studies that did not have any of the desired outcome measures or a sedentary control group were excluded. Several authors were contacted to provide missing data or to clarify if data were duplicated in multiple publications. Incomplete data, or data from an already included study, were excluded. Studies using interventions other than pure isometric exercise (for example, aerobic or dynamic resistance exercise) were excluded.

\section{Studies included in the review}

Our initial search identified 1288 manuscripts, examination of the latest editions of relevant journals yielded a further 2 manuscripts. Out of 1290 studies, 368 were excluded at first inspection as duplicates, 152 were removed after reading titles or abstracts, 598 studies were not trials of isometric exercise therapy adults, leaving 172 studies; 159 were not randomized-controlled trials with a duration of 2 weeks or longer and 2 others were excluded because of data duplication, leaving 11 included studies (14 intervention groups as 3 studies had more than 1 intervention group) for analysis (see Figure 1).

\section{Data synthesis}

Information on outcome measures was archived in a database. The outcome measures were SBP, DBP, MAP (which was calculated by study authors by adding diastolic plus one-third pulse pressure) and heart rate.

\section{Statistical analysis}

Meta-analyses were completed for continuous data by using the change in the mean and standard deviation of outcome measures. It is an accepted practice to only use post-intervention data for meta-analysis but this method assumes that random allocation of participants always creates intervention groups matched at baseline for age, disease severity and so on. Change in post-intervention mean was calculated by subtracting baseline from post-intervention values. Change in the standard deviation of post-intervention outcomes was calculated by using Revman 5.2 (Nordic Cochrane Centre, Copenhagen, Denmark). Data required was either (i) 95\% confidence interval data for pre-post intervention change for each group, or when this was unavailable, (ii) actual $P$-values for pre-post intervention change for each group, or if only the level of statistical significance was available (iii) we tried, where possible, to obtain precise $P$ values (for example, $P=0.034$ ) or $95 \%$ confidence intervals from authors. We attempted where possible to obtain these precise data, but if these data were not forthcoming then we used default $P$-values, for example, $P<0.05$ becomes $P=0.049$, and $P=$ not significant becomes $P=0.05$. We conducted analyses for
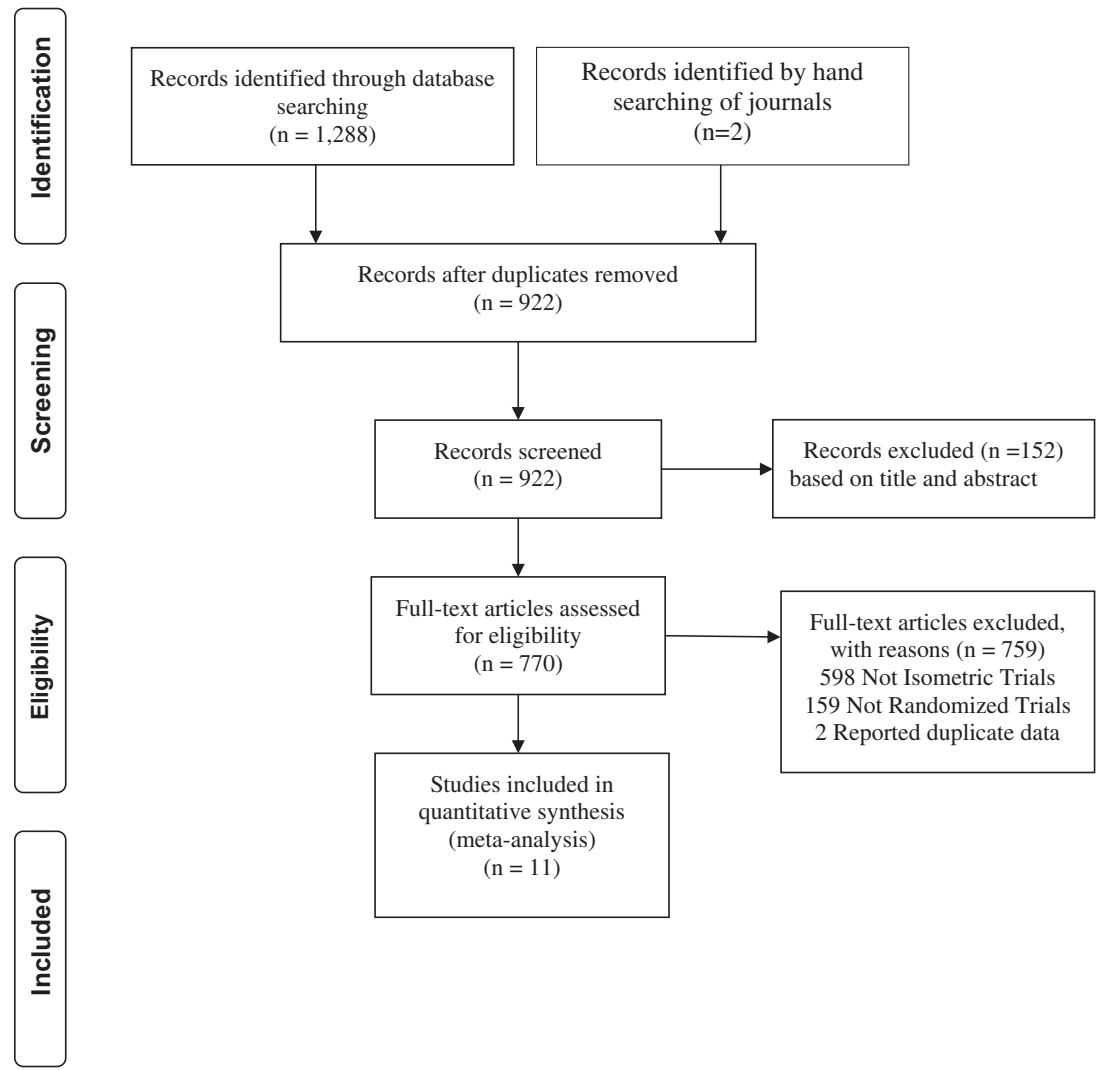

Studies included in quantitative synthesis (meta-analysis) $(\mathrm{n}=11)$

Figure 1 Consort statement. 
SBP, DBP and MAP. We also conducted the following sub-analyses; male vs female, age $\geqslant 45$ vs $<45$ years, intervention $>8$ weeks vs $\leqslant 8$ weeks, unilateral vs bilateral limb IRT, arm vs leg IRT and hypertensive vs normotensive. The BP results represent the net effect or the change in the exercising group, minus the change in the control group, described as the mean difference (MD). A fixed effects model was used unless heterogeneity was $>75 \%$, in which case a random effects inverse variance was used with the effects measure of $\mathrm{MD}$, which indicates which group, if any, shows a benefit, so the analysis is twotailed. We examined whether the $95 \%$ CIs overlapped between sub-groups; if not, then this indicated a significant difference between sub-groups.

Heterogeneity was quantified using the Cochrane Q test. ${ }^{16}$ Egger plots were provided to assess the risk of publication bias. Study quality was assessed by using the TESTEX scale (maximum score $=15$ ). ${ }^{17}$ We used a $5 \%$ level of significance and 95\% confidence intervals; all figures were produced using Revman 5.2. A PRISMA statement can be seen in the Supplementary Files.

\section{RESULTS}

Eleven studies ${ }^{18-28}$ were included in our analysis, totaling 302 participants (Table 1). Ten studies are RCTs and one crossover study by Devereux et al. ${ }^{22}$ which reported baseline BP before randomization. Six studies used handgrip and five studies used leg exercise. None of the studies reported any adverse events from isometric exercise. Six studies used automated BP measurements, two others used Doppler

\section{Table 1 Characteristics of included studies}

\begin{tabular}{|c|c|c|c|c|c|}
\hline $\begin{array}{l}\text { Study and } \\
\text { country }\end{array}$ & $\begin{array}{l}\text { Duration } \\
\text { (weeks) }\end{array}$ & Participants & Withdrawal & Frequency & Exercise training characteristics \\
\hline $\begin{array}{l}\text { Badrov et al. }{ }^{18} \\
\text { Canada }\end{array}$ & 8 & $\begin{array}{l}\text { Women }(n=36) \\
16-32 \text { years }\end{array}$ & $\begin{array}{l}3 \text { controls } \\
15 x / \text { week }\end{array}$ & 3/5 Days per week & $\begin{array}{l}4 \times 2 \text { min unilateral IHG contractions at } 30 \% \text { MVC, separated by } 4 \text { min of rest. } \\
\text { All contractions in non-dominant hand. } \\
3 \times \text { per week group }(n=12), 5 \times \text { per week group }(n=11) \text {, controls }(n=9) \text {. }\end{array}$ \\
\hline $\begin{array}{l}\text { Badrov et al. }{ }^{19} \\
\text { Canada }\end{array}$ & 10 & $\begin{array}{l}\text { Men }(n=13) \\
\text { Women }(n=11) \\
51-74 \text { years } \\
\text { Hypertensive } \\
\text { medicated }\end{array}$ & None & 3 Days per week & $\begin{array}{l}4 \times 2 \text { min IHG bilateral contractions at } 30 \% \text { MVC, separated by } 1 \text {-min } \\
\text { rest periods ( } n=12) \\
\text { Non-exercising controls }(n=12) \text {, no intervention. } \\
\text { Participants recorded any changes in exercise, diet and medication. }\end{array}$ \\
\hline $\begin{array}{l}\text { Baross et al. }{ }^{21} \\
\text { UK }\end{array}$ & 8 & $\begin{array}{l}\text { Men }(n=30) \\
45-60 \text { years }\end{array}$ & None & 3 Days per week & $\begin{array}{l}4 \times 2 \text { min double-leg extension isometric exercises at } 14 \% \text { MVC, } \\
\text { separated by } 2 \text {-min rest periods. } \\
14 \% \text { MVC ( } n=10) ; 8 \% \text { MVC }(n=10) \\
\text { Controls remained sedentary }(n=10)\end{array}$ \\
\hline $\begin{array}{l}\text { Baross et al. }{ }^{20} \\
\text { UK }\end{array}$ & 8 & $\begin{array}{l}\text { Men }(n=20) \\
45-60 \text { years }\end{array}$ & None & 3 Days per week & $\begin{array}{l}4 \times 2 \text { min double-leg extension isometric exercises at } 85 \% \mathrm{HR}_{\text {peak }} \text {, } \\
\text { separated by } 2 \text {-min rest periods }(n=10) \\
\text { Controls remained sedentary }(n=10)\end{array}$ \\
\hline $\begin{array}{l}\text { Devereux } \\
\text { et al. }{ }^{22} \\
\text { UK }\end{array}$ & 4 & $\begin{array}{l}\text { Men }(n=13) \\
21.0 \pm 2.4 \text { years }\end{array}$ & Unknown & 3 Days per week & $\begin{array}{l}\text { Four } \times 2 \text { min bilateral leg isometric exercise at } 95 \% \mathrm{HR}_{\text {peak }} \text {, separated } \\
\text { by } 3 \text {-min rest periods. } \\
\text { No control group. }\end{array}$ \\
\hline $\begin{array}{l}\text { Gill et al. }{ }^{23} \\
\text { USA }\end{array}$ & 3 & $\begin{array}{l}\text { Men }(n=11) \\
\text { Women }(n=29) \\
22.3 \pm 3.4 \text { years }\end{array}$ & 5 & 3 Days per week & $\begin{array}{l}4 \times 2 \text { min bilateral leg isometric exercise, separated by 3-min rest periods. } \\
20 \% \text { EMGpeak-23\% MVC }(n=8) ; 30 \% \text { EMGpeak-34\% MVC }(n=9) \\
\text { Controls }(n=18) \text {, no intervention. }\end{array}$ \\
\hline $\begin{array}{l}\text { Millar et al. }{ }^{24} \\
\text { Canada }\end{array}$ & 8 & $\begin{array}{l}\text { Men }(n=21) \\
\text { Women }(n=28) \\
66.4 \pm 0.9 \text { years }\end{array}$ & None & 3 Days per week & $\begin{array}{l}4 \times 2 \text { min alternating bilateral IHG contractions at } 30-40 \% \text { MVC, } \\
\text { separated by } 1 \text {-min rest periods }(n=25) \text {. } \\
\text { Controls ( } n=24 \text { ) engaged in a brief }(10 \mathrm{~min} \text { ) weekly one-on-one session } \\
\text { relating to hypertension. }\end{array}$ \\
\hline $\begin{array}{l}\text { Stiller- } \\
\text { Moldovan } \\
\text { et al. }{ }^{25} \\
\text { Canada }\end{array}$ & 8 & $\begin{array}{l}\text { Men }(n=10) \\
\text { Women }(n=10) \\
\text { Exercise } \\
60.0 \pm 8.5 \text { years } \\
\text { Control } \\
62.7 \pm 6.1 \text { years } \\
\text { Hypertensive } \\
\text { medicated }\end{array}$ & $\begin{array}{l}n=25 \\
2 \text { Training } \\
3 \text { Controls }\end{array}$ & 3 Days per week & $\begin{array}{l}4 \times 2 \text { min alternating IHG contractions at } 30 \% \text { MVC, separated } \\
\text { by } 1 \text {-min rest periods }(n=11) \\
\text { Controls }(n=9) \text {. } \\
\text { * Numbers of participants does not include dropouts }\end{array}$ \\
\hline $\begin{array}{l}\text { Taylor et al. }{ }^{26} \\
\text { Canada }\end{array}$ & 10 & $\begin{array}{l}\text { Men }(n=10) \\
\text { Women }(n=7) \\
60-80 \text { years } \\
(\bar{x}=67.5) \\
\text { Hypertensive } \\
\text { medicated }\end{array}$ & Unknown & 3 Days per week & $\begin{array}{l}4 \times 2 \text { min IHG contractions at } 30 \% \text { MVC using alternate hands, } \\
\text { separated by } 1 \text {-min rest periods }(n=9) \text {. } \\
\text { Controls }(n=8) \text {. }\end{array}$ \\
\hline $\begin{array}{l}\text { Wiles et al. }{ }^{27} \\
\text { UK }\end{array}$ & 8 & $\begin{array}{l}\text { Men }(n=33) \\
18-34 \text { years }\end{array}$ & None & 3 Days per week & $\begin{array}{l}4 \times 2 \text { min double-leg extension isometric exercise, separated by } 2 \text {-min rest periods. } \\
\mathrm{HI}-95 \% \mathrm{HR}_{\text {peak }}-21 \% \mathrm{MVC}(n=11) ; \mathrm{LO}-75 \% \mathrm{HR}_{\text {peak }}-10 \% \mathrm{MVC}(n=11) \\
\text { Controls }(n=11)\end{array}$ \\
\hline $\begin{array}{l}\text { Wiley et al. }{ }^{28} \\
\text { USA }\end{array}$ & 8 & $\begin{array}{l}n=20 \\
20-35 \text { years }\end{array}$ & $\begin{array}{l}2 \text { Training } \\
3 \text { Controls }\end{array}$ & 3 Days per week & $\begin{array}{l}4 \times 2 \text { min unilateral IHG contractions at } 30 \% \text { of MVC, separated by } 3 \text {-min rest periods. } \\
\text { Contractions completed in dominant arm }(n=8) . \\
\text { Controls ( } n=7 \text { after } 3 \text { dropped out). }\end{array}$ \\
\hline
\end{tabular}

Abbreviations: EMG, electromyography; HI, high; HR, heart rate; IHG, isometric handgrip; LO, low; MVC, maximum voluntary contraction. 
analyses and three used auscultation, but methods were not otherwise standardized. The study by Stiller-Moldovan et al. ${ }^{25}$ is the only work to report both single and ambulatory BP measurements.

\section{Primary analyses}

SBP was significantly reduced with a MD of $-5.20 \mathrm{~mm} \mathrm{Hg}(95 \% \mathrm{CI}$ -6.08 to $-4.33, P<0.00001, I^{2}=71 \%$; see Figure 2 ).

DBP was significantly reduced with a MD of $-3.91 \mathrm{~mm} \mathrm{Hg}(95 \%$ CI -5.68 to $-2.14, P<0.0001, I^{2}=86 \%$; see Figure 3 ).

MAP was reduced with a MD of $-3.33 \mathrm{~mm} \mathrm{Hg}(95 \% \mathrm{CI}-4.01$ to $-2.66, P<0.00001, I^{2}=61 \%$; see Figure 4).

Heart rate (beats $\mathrm{min}^{-1}$ ) was significantly reduced by a $\mathrm{MD}$ of -1.42 beats $\min ^{-1}\left(95 \%\right.$ CI $-2.64,-0.20, P=0.02, I^{2}=77 \%$; see Figure 5).

\section{Sub-analyses}

Sub-analyses are shown in Table 2. Please note results in bold identify significant differences between sub-groups.

Gender. Males tended to reduce MAP more than females with MD $-4.13 \mathrm{~mm} \mathrm{Hg}\left(95 \% \mathrm{CI}-5.08\right.$ to $\left.-3.18, I^{2}=0 \%\right)$ vs females $\mathrm{MD}$
$-2.29 \mathrm{~mm} \mathrm{Hg}\left(95 \% \mathrm{CI}-3.87\right.$ to $\left.-0.71, I^{2}=0 \%\right)$, noting $95 \%$ CIs overlap slightly. No significant differences for change in SBP, DBP or heart rate were observed in males vs females.

Age. Those subjects aged 45 years or over demonstrated larger reductions in MAP than those under 45 years, noting 95\% CIs do not overlap, $\geqslant 45$ years $\mathrm{MD}-5.51 \mathrm{~mm} \mathrm{Hg}(95 \% \mathrm{CI}-6.95$ to -4.06 , $\left.I^{2}=0 \%\right)$ vs those $<45$ years $\mathrm{MD}-2.72 \mathrm{~mm} \mathrm{Hg}(95 \% \mathrm{CI}-3.49$ to $-1.96, I^{2}=58 \%$ ). No significant differences for change in SBP, DBP or heart rate were observed between age categories.

Duration. Those subjects undertaking 8 weeks or more of IRT demonstrated a larger reduction in SBP MD $-7.26 \mathrm{~mm} \mathrm{Hg}$ (95\% CI -8.47 to $-6.04, I^{2}=52 \%$ ) than those undertaking less than 8 weeks IRT MD $-2.99 \mathrm{~mm} \mathrm{Hg}\left(95 \% \mathrm{CI}-4.25\right.$ to $\left.-1.73, I^{2}=0 \%\right)$, noting 95\% CIs do not overlap. Those subjects undertaking 8 weeks or more of IRT demonstrated a larger reduction in MAP MD $-4.22 \mathrm{~mm} \mathrm{Hg}$ $\left(95 \% \mathrm{CI}-5.08\right.$ to $\left.-3.37, I^{2}=34 \%\right)$ than those undertaking $<8$ weeks IRT MD $-1.85 \mathrm{~mm} \mathrm{Hg}\left(95 \% \mathrm{CI}-2.95\right.$ to $\left.-0.74, I^{2}=54 \%\right)$, noting 95\% CIs do not overlap. No significant difference for change in DBP or heart rate was observed between IRT duration categories.

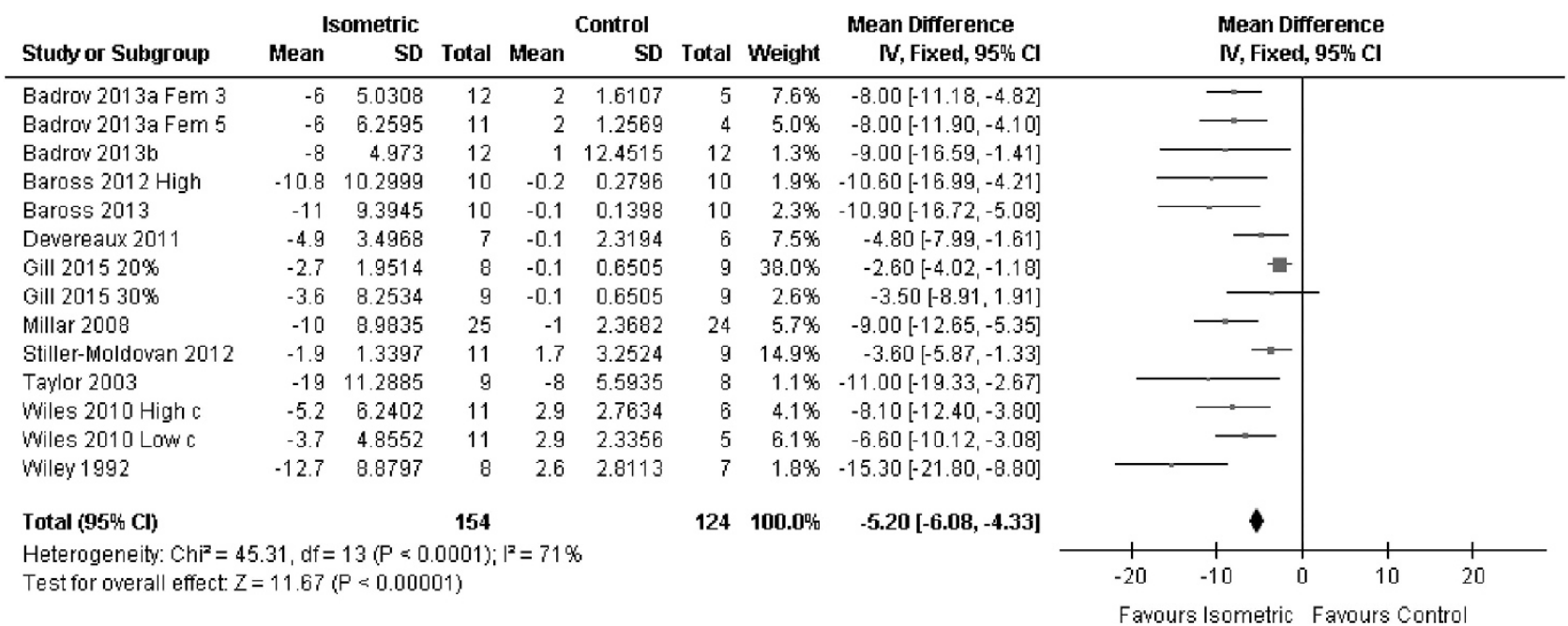

Figure 2 Analysis of change in systolic blood pressure.

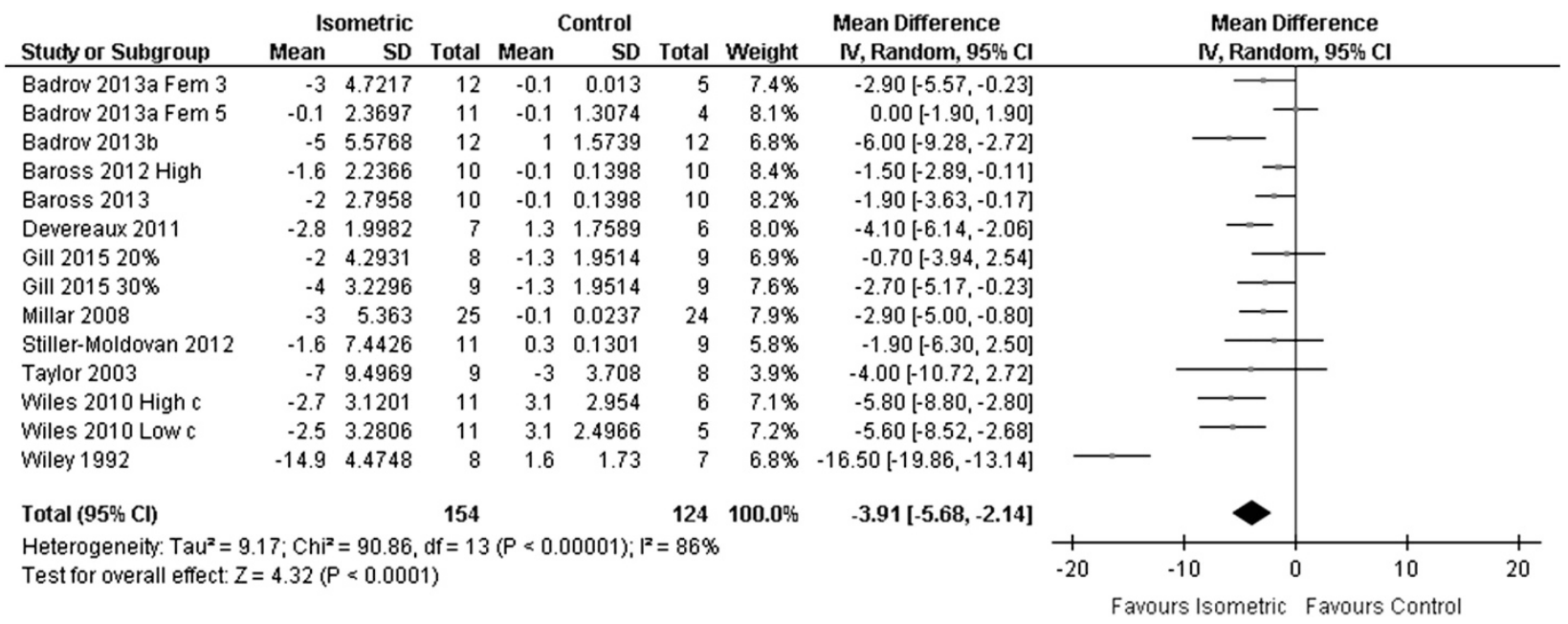

Figure 3 Analysis of change in diastolic blood pressure. 


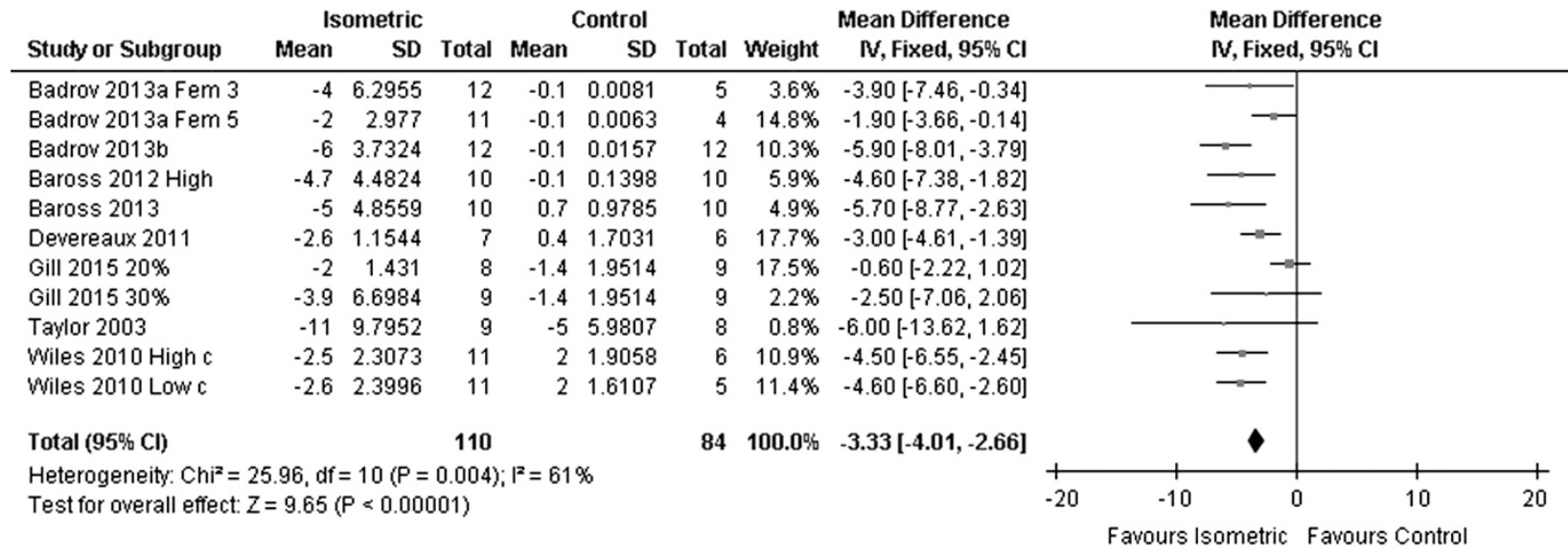

Figure 4 Analysis of change in mean arterial blood pressure.

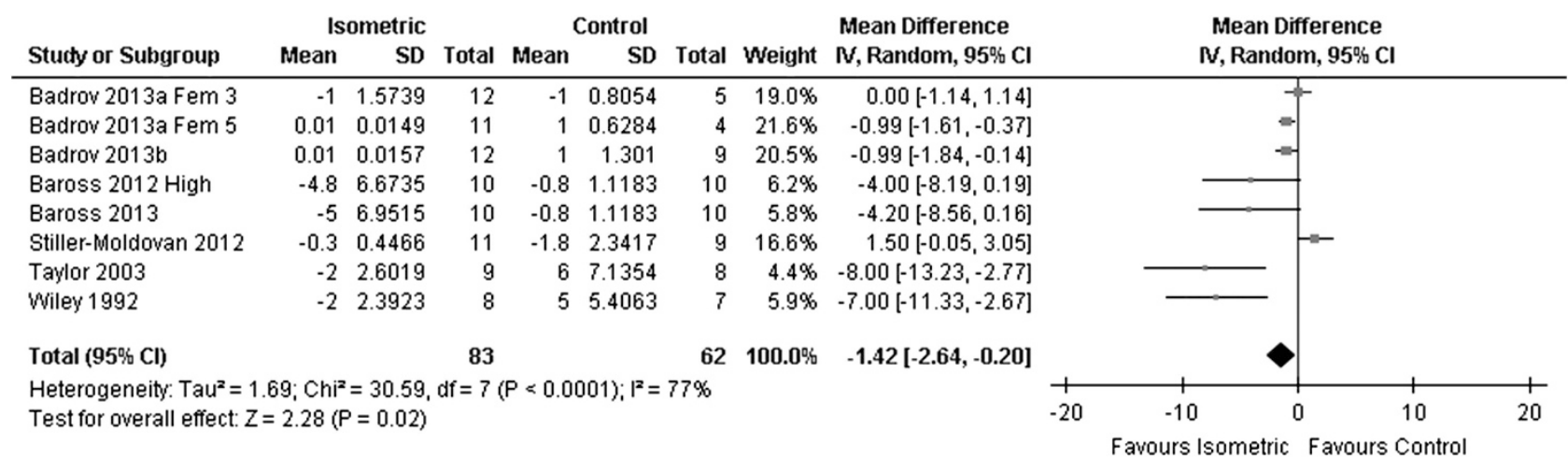

Figure 5 Analysis of change in resting heart rate.

Unilateral. Those subjects undertaking unilateral IRT demonstrated a larger reduction in SBP MD $-8.92 \mathrm{~mm} \mathrm{Hg}$ (95\% CI -11.22 to $\left.-6.61, I^{2}=53 \%\right)$ than those undertaking bilateral IRT MD -4.58 $\mathrm{mm} \mathrm{Hg}\left(95 \% \mathrm{CI}-5.52\right.$ to $\left.-3.63, I^{2}=66 \%\right)$, noting 95\% CIs do not overlap. No significant differences for change in DBP, MAP or heart rate were observed between unilateral and bilateral categories.

Arm. Those subjects undertaking arm IRT demonstrated a larger reduction in SBP $\mathrm{MD}-6.88 \mathrm{~mm} \mathrm{Hg}(95 \% \mathrm{CI}-8.31$ to -5.46 , $\left.I^{2}=66 \%\right)$ than those undertaking lower limb IRT MD $-4.20 \mathrm{~mm} \mathrm{Hg}$ (95\% CI -5.30 to $-3.09, I^{2}=68 \%$ ), noting $95 \%$ CIs do not overlap. No significant differences for change in DBP, MAP or heart rate were observed between limb categories.

Hypertension status. Hypertensive participants in IRT demonstrated a larger reduction in MAP MD - $5.91 \mathrm{~mm} \mathrm{Hg}(95 \% \mathrm{CI}-7.94$ to -3.87 , $\left.I^{2}=0 \%\right)$ than normotensive participants $\mathrm{MD}-3.01 \mathrm{~mm} \mathrm{Hg}(95 \% \mathrm{CI}$ -3.73 to $-2.29, I^{2}=58 \%$ ), noting $95 \%$ CIs do not overlap. No significant differences for change in SBP, DBP or heart rate were observed between hypertension categories.

Ambulatory BP monitoring. We removed the study that reported ambulatory BP measurements from our primary analyses; however, removal of these data from our primary analyses does not alter the SBP and DBP findings.
Study quality assessment

Study quality and reporting was assessed using the TESTEX scale, median score was 10 out of a scale of 15 (higher score indicates better quality). Four studies scored 9 and seven scored 10 (see Supplementary Files, Supplementary Table S1).

\section{Heterogeneity}

Heterogeneity was not high in any of the analyses or sub-analyses where between group 95\% CIs did not overlap. Heterogeneity was higher in the analyses of diastolic BP and heart rate.

\section{Publication bias}

Egger Plots showed minimal evidence of publication bias (see Supplementary Files, Supplementary Figures S2-S4).

\section{DISCUSSION}

Our updated systematic review and subsequent meta-analysis confirms previous findings that IRT reduces arterial BP. The BP reductions were observed in SBP, DBP and MAP and were consistent across included trials. BP reductions appear to be larger in hypertensive males and those over 45 years of age. Certain IRT training regimes also produced larger BP reductions, for example, unilateral arm IRT for $>8$ weeks duration.

Our results showed that SBP was lowered almost $6 \mathrm{~mm} \mathrm{Hg}$ in response to isometric training, which is a similar effect size to the SBP fall in our previous meta-analyses. ${ }^{8}$ Although the inclusion of the 
Table 2 Isometric resistance training: sub-analyses

\begin{tabular}{|c|c|c|c|c|c|c|c|c|}
\hline & \multicolumn{2}{|c|}{ Systolic blood pressure } & \multicolumn{2}{|c|}{ Diastolic blood pressure } & \multicolumn{2}{|c|}{ Mean arterial pressure } & \multicolumn{2}{|r|}{ Resting heart rate } \\
\hline & $\mathrm{N}$ & Effect size $(95 \% \mathrm{Cl})$ & N & Effect size $(95 \% \mathrm{Cl})$ & $\mathrm{N}$ & Effect size $(95 \% \mathrm{Cl})$ & $\mathrm{N}$ & Effect size $(95 \% \mathrm{Cl})$ \\
\hline \multicolumn{9}{|l|}{ Gender } \\
\hline Male & $86(4)$ & $-7.05(-8.91,-5.18)$ & $86(4)$ & $-2.80(-3.67,-1.93)$ & $86(4)$ & $-4.13(-5.08,-3.18)$ & $40(2)$ & $-4.10(-7.12,-1.07)$ \\
\hline Female & $32(1)$ & $-8.00(-10.46,-5.54)$ & $32(1)$ & $-0.97(-2.52,0.57)$ & $32(1)$ & $-2.29(-3.87,-0.71)$ & $32(1)$ & $-0.77(-1.31,-0.22)$ \\
\hline$\geqslant 45$ years & $150(6)$ & $-6.39(-8.07,-4.72)$ & $150(6)$ & $-2.26(-3.16,-1.36)$ & $81(4)$ & $-5.51(-6.95,-4.06)$ & $98(5)$ & $-0.77(-1.48,-0.05)$ \\
\hline
\end{tabular}

\title{
Duration of the
}

intervention

$<8$ weeks

48 (2) $-2.99(-4.25,-1.73)$

48 (2) $-2.99(-4.40,-1.57)$

48 (2) $-1.85(-2.95,-0.74) \quad N A$

Not estimable

$\geqslant 8$ weeks

230 (9) $-7.26(-8.47,-6.04)$

$230(9)-3.02(-3.73,-2.31)$

146 (6)

$-4.22(-5.08,-3.37)$

145 (7) $-0.83(-1.26,-0.40)$

Unilateral or bilateral

Unilateral

47 (2) $-8.92(-11.22,-6.61)$

$47(2)-3.70(-5.10,-2.29) \quad 32(1)-2.29(-3.87,-0.71)$

$47(2)-0.86(-1.40,-0.32)$

Bilateral

$231(9)-4.58(-5.52,-3.63)$

$231(9)-2.84(-3.55,-2.13)$

162 (7) $-3.57(-4.31,-2.82)$

98 (5) $-0.77(-1.48,-0.05)$

\section{Limbs \\ Arm \\ Leg}

\author{
157 (6) $-6.88(-8.31,-5.46)$
}

$157(6)-3.64(-4.69,-2.58) \quad 73(3)-3.65(-4.90,-2.40) \quad 105(5)-0.76(-1.19,-0.32)$

$121(5)-4.20(-5.30,-3.09)$

$121(5)-2.66(-3.46,-1.87) \quad 121(5) \quad-3.20(-4.00,-2.39) \quad 40(2)-4.10(-7.12,-1.07)$

\section{Hypertensive or}

normotensive

Hypertensive

$61(3)-4.49(-6.59,-2.38)$

$61(3)-4.46(-6.91,-2.02) \quad 41(2)-5.91(-7.94,-3.87)$

58 (3) $-0.57(-1.30,0.17)$

Normotensive

$217(8)-5.35(-6.31,-4.39)$

$217(8)-2.91(-3.57,-2.25) \quad 153(6)-3.01(-3.73,-2.29)$

87 (4) $-0.96(-1.49,-0.43)$

Abbreviations: $\mathrm{Cl}$, confidence interval; $\mathrm{NA}$, not available.

$\mathrm{N}$ is the number of participants whereas the number in parentheses represents the number of studies—results in bold indicate significant differences are present $(95 \%$ confidence intervals do not overlap).

recently published trials increases statistical power of this analysis, there is a small decrease in the absolute effect size, compared with our earlier work. ${ }^{8}$ Nevertheless the effect size remains highly significant with a relatively small confidence interval and substantiates the recent inclusion by the American Heart Association of isometric exercise as a potential non-pharmacologic therapy to lower BP. ${ }^{29}$ Furthermore, the effect size lends weight to the notion that isometric exercise training is comparable or superior to dynamic-exercise training (aerobic or resistance) or combined dynamic exercise for reducing systolic BP. Although the reductions in DBP and MAP are smaller than those seen in SBP, the effect sizes are at least comparable with changes observed from other exercise modalities. ${ }^{7}$

Our secondary analyses appear to demonstrate that there is greater potential for BP lowering in people with greater risk of hypertension. In our sub-analyses males, those aged 45 or over and people with hypertension showed larger reductions in some BP measurements. These findings are similar to previous work ${ }^{7}$ and we believe this is probably because older, hypertensive people are more likely to be deconditioned and therefore have greater potential for improvement. It also notable that BP reductions were observed independent of weight loss. Previous work has shown weight loss to have antihypertensive effects in older adults. ${ }^{30}$ Certain aspects of the delivery of IRT appear to optimize the potential anti-hypertensive benefit, for example IRT lasting 8 weeks or longer appears to be optimal. It may be that 8 weeks or more is desirable to elicit optimal anti-hypertensive changes. It is possible that longer training periods are required to initiate regional alterations in ventricular function, as described previously. ${ }^{31}$ Arm IRT appears to be superior to leg IRT, this may be explained by the fact that the active muscle mass is smaller in the arm so the threshold at which the arteries become occluded may also be lower. This is relevant as we believe that repeated exposure to arterial occlusion, leading to repeated bouts of hypoxia in the forearm are the stimulus for changes in arterial stiffness. ${ }^{32}$ We are, however, unclear about which metabolites, formed during hypoxic episodes, are precisely responsible for $\mathrm{BP}$ reductions. Regardless of the mechanistic explanation, health practitioners and those with hypertension can perhaps exploit benefit from the simplicity and relatively low cost of administering isometric resistance exercise.

Low-to-moderate intensity isometric activity can be performed anywhere, requires relatively inexpensive equipment and does not elicit the same level of cardiovascular stress (for example, rate-pressure product) as aerobic activity. Relative to aerobic activity, isometric exercise has the potential for superior adherence owing to simplicity, lower cost and perhaps less exercise time.

We recommend isometric handgrip exercise may produce greatest reduction in $\mathrm{BP}$ in hypertensive males aged $\geqslant 45$ years, using unilateral arm IRT, $4 \times 2 \mathrm{~min}$, three times weekly at $30 \%$ MVC, for $>8$ weeks. We strongly recommend that future studies should report ambulatory BP monitoring values.

\section{Limitations}

Our analyses exhibit moderate-to-high evidence of between-study heterogeneity. Although most comparisons of exercise training studies show variations in study duration and exercise modality, the 
commonality of protocols renders differences negligible in this analysis. Although the investigators performing assessment measures were aware of group assignment; this was not necessarily a limitation as we utilized the TESTEX scale ${ }^{17}$ to assess study quality as all studies would have found it difficult to blind participants and investigators to the allocation of isometric exercise training or sedentary control. Median TESTEX score was 10 suggesting a good-to-moderate study design and reporting. Future studies should seek to employ sham isometric training (such as at a sub-optimal intensity) to permit studies to use a stronger double-blind design. The Egger plots showed minimal evidence of publication bias, which is understandable as studies show consistent improvements and authors are apt to emphasize the anti-hypertensive benefits. It is therefore unlikely unpublished negative or neutral data sets exist for the majority of our outcome measures and the level of significance suggest unpublished data would not change the findings presented here.

The major limitation of this field of study is that several desired measures such as continuous BP monitoring, neuro-hormonal and blood vessel compliance and flow are unavailable, making it difficult to unravel the mechanistic interpretation of these anti-hypertensive findings.

\section{CONCLUSIONS}

IRT lowers SBP, DBP and MAP. The magnitude of effect may be larger in hypertensive males aged $\geqslant 45$ years, using unilateral arm IRT for $>8$ weeks. Our data suggest that this form of training has the potential to produce significant and clinically meaningful BP reductions and could serve as an adjunct exercise modality.

\section{CONFLICT OF INTEREST}

The authors declare no conflict of interest.

1 Heidenreich PA, Trogdon JG, Khavjou OA, Butler J, Dracup K, Ezekowitz MD, Finkelstein EA, Hong Y, Johnston SC, Khera A, Lloyd-Jones DM, Nelson SA, Nichol G, Orenstein D, Wilson PW, Woo YJ. Forecasting the future of cardiovascular disease in the United States: a policy statement from the American Heart Association. Circulation 2011; 123: 933-944.

2 Hajjar I, Kotchen TA. Trends in prevalence, awareness, treatment, and control of hypertension in the United States, 1988-2000. JAMA 2003; 290: 199-206.

3 Chobanian AV, Bakris GL, Black HR, Cushman WC, Green LA, Izzo JL Jr., Jones DW, Materson BJ, Oparil S, Wright JT Jr., Roccella EJ. Seventh report of the Joint National Committee on Prevention, Detection, Evaluation, and Treatment of High Blood Pressure. Hypertension 2003; 42: 1206-1252.

4 Mancia G, Fagard R, Narkiewicz K, Redon J, Zanchetti A, Bohm M, Christiaens T, Cifkova R, De Backer G, Dominiczak A, Galderisi M, Grobbee DE, Jaarsma T, Kirchhof $P$, Kjeldsen SE, Laurent $S$, Manolis AJ, Nilsson PM, Ruilope LM, Schmieder RE, Sirnes PA, Sleight P, Viigimaa M, Waeber B, Zannad FTask Force M. 2013 ESH/ESC Guidelines for the management of arterial hypertension: the Task Force for the management of arterial hypertension of the European Society of Hypertension (ESH) and of the European Society of Cardiology (ESC). J Hypertens 2013; 31: 1281-1357.

5 Mosca L, Benjamin EJ, Berra K, Bezanson JL, Dolor RJ, Lloyd-Jones DM, Newby LK, Pina IL, Roger VL, Shaw LJ, Zhao D, Beckie TM, Bushnell C, D'Armiento J, Kris-Etherton PM, Fang J, Ganiats TG, Gomes AS, Gracia CR, Haan CK, Jackson EA, Judelson DR, Kelepouris E, Lavie CJ, Moore A, Nussmeier NA, Ofili E, Oparil S, Ouyang P, Pinn VW, Sherif K, Smith SC Jr., Sopko G, Chandra-Strobos N, Urbina EM, Vaccarino V, Wenger NK. Effectiveness-based guidelines for the prevention of cardiovascular disease in women-2011 update: a guideline from the American Heart Association. J Am Coll Cardiol 2011; 57: 1404-1423.

6 Carlson DJ, Dieberg G, Hess N, Millar P, Smart NA. Isometric exercise training for blood pressure management: a systematic review and meta-analysis. Mayo Clin Proc 2014; 89.
7 Cornelissen VA, Buys R, Smart NA. Endurance exercise beneficially affects ambulatory blood pressure: a systematic review and meta-analysis. J Hypertens 2013; 31: 639-648.

8 Cornelissen VA, Smart NA. Exercise training for blood pressure: a systematic review and meta-analysis. J Am Heart Assoc 2013; 2: e004473.

9 Linke SE, Gallo LC, Norman GJ. Attrition and adherence rates of sustained vs. intermittent exercise interventions. Ann Behav Med 2011; 42: 197-209.

10 Ramos RA, Guimaraes FS, Cordovil I, de Sa Ferreira A. The six-minute walk distance is a marker of hemodynamic-related functional capacity in hypertension: a casecontrol study. Hypertens Res 2014; 37: 746-752.

11 Owen A, Wiles J, Swaine I. Effect of isometric exercise on resting blood pressure: a meta analysis. J Hum Hypertens 2010; 24: 796-800.

12 Kelley GA, Kelley KS. Isometric handgrip exercise and resting blood pressure: a metaanalysis of randomized controlled trials. J Hypertens 2010; 28: 411-418.

13 Cornelissen VA, Goetschalckx K, Verheyden B, Aubert AE, Arnout J, Persu A, Rademakers $\mathrm{F}$, Fagard $\mathrm{RH}$. Effect of endurance training on blood pressure regulation, biomarkers and the heart in subjects at a higher age. Scand J Med Sci Sports 2011; 21: 526-534.

14 Cornelissen VA, Fagard RH, Coeckelberghs E, Vanhees L. Impact of resistance training on blood pressure and other cardiovascular risk factors: a meta-analysis of randomized, controlled trials. Hypertension 2011; 58: 950-958.

15 Kelley GA, Kelley KS. Progressive resistance exercise and resting blood pressure: a meta-analysis of randomized controlled trials. Hypertension 2000; 35: 838-843.

16 Higgins JP, Altman DG, Gotzsche PC, Juni P, Moher D, Oxman AD, Savovic J, Schulz KF, Weeks L, Sterne JA, Cochrane Bias Methods GCochrane Statistical Methods G. The Cochrane Collaboration's tool for assessing risk of bias in randomised trials. BMJ 2011; 343: d5928.

17 Smart NA, Waldron M, Ismail H, Giallauria F, Vigorito C, Cornelissen V, Dieberg G. Validation of a new tool for the assessment of study quality and reporting in exercise training studies: TESTEX. Int J Evid Based Healthc 2015; 13: 9-18.

18 Badrov MB, Bartol CL, Dibartolomeo MA, Millar PJ, McNevin NH, McGowan CL. Effects of isometric handgrip training dose on resting blood pressure and resistance vessel endothelial function in normotensive women. Eur J Appl Physiol 2013; 113: 2091-2100.

19 Badrov MB, Horton S, Millar PJ, McGowan CL. Cardiovascular stress reactivity tasks successfully predict the hypotensive response of isometric handgrip training in hypertensives. Psychophysiology 2013; 50: 407-414.

20 Baross A, Wiles JD, Swaine IL. Double-leg isometric exercise in older men. Open Access J Sports Med 2013; 4: 33-40.

21 Baross AW, Wiles JD, Swaine IL. Effects of the intensity of leg isometric training on the vasculature of trained and untrained limbs and resting blood pressure in middleaged men. Int J Vasc Med 2012; 2012: 964697.

22 Devereux GR, Wiles JD, Swaine I. Markers of isometric training intensity and reductions in resting blood pressure. J Sports Sci 2011; 29: 715-724.

23 Gill KF, Arthur ST, Swaine I, Devereux GR, Huet YM, Wikstrom E, Cordova ML, Howden R. Intensity-dependent reductions in resting blood pressure following shortterm isometric exercise training. J Sports Sci 2015; 33: 616-621.

24 Millar PJ, Bray SR, MacDonald MJ, McCartney N. The hypotensive effects of isometric handgrip training using an inexpensive spring handgrip training device. J Cardiopulm Rehabil Prev 2008; 28: 203-207.

25 Stiller-Moldovan C, Kenno K, McGowan CL. Effects of isometric handgrip training on blood pressure (resting and $24 \mathrm{~h}$ ambulatory) and heart rate variability in medicated hypertensive patients. Blood Press Monit 2012; 17: 55-61.

26 Taylor AC, McCartney N, Kamath MV, Wiley RL. Isometric training lowers resting blood pressure and modulates autonomic control. Med Sci Sports Exerc 2003; 35: 251-256.

27 Wiles JD, Coleman DA, Swaine IL. The effects of performing isometric training at two exercise intensities in healthy young males. Eur J Appl Physiol 2010; 108: 419-428.

28 Wiley RL, Dunn CL, Cox RH, Hueppchen NA, Scott MS. Isometric exercise training lowers resting blood pressure. Med Sci Sports Exerc 1992; 24: 749-754.

29 Brook RD, Appel LJ, Rubenfire M, Ogedegbe G, Bisognano JD, Elliott WJ, Fuchs FD, Hughes JW, Lackland DT, Staffileno BA, Townsend RR, Rajagopalan S, American Heart Association Professional Education Committee of the Council for High Blood Pressure Research CoCStroke Nursing CoEPreventionCouncil on Nutrition PA. Beyond medications and diet: alternative approaches to lowering blood pressure: a scientific statement from the american heart association. Hypertension 2013; 61: 1360-1383.

30 Kawamoto R, Kohara K, Katoh T, Kusunoki T, Ohtsuka N, Abe M, Kumagi T, Miki T. Effect of weight loss on central systolic blood pressure in elderly community-dwelling persons. Hypertens Res 2014; 37: 933-938.

31 Leggio M, Mazza A, Cruciani G, Sgorbini L, Pugliese M, Bendini MG, Severi P, Jesi AP. Effects of exercise training on systo-diastolic ventricular dysfunction in patients with hypertension: an echocardiographic study with tissue velocity and strain imaging evaluation. Hypertens Res 2014; 37: 649-654.

32 Davies TS, Frenneaux MP, Campbell RI, White MJ. Human arterial responses to isometric exercise: the role of the muscle metaboreflex. Clin Sci 2007; 112: 441-447.

Supplementary Information accompanies the paper on Hypertension Research website (http://www.nature.com/hr) 